\title{
Genetic Distances of Scallop (Chlamys farreri) Populations investigated by PCR Procedure
}

\author{
$\dagger$ Jong-Man Yoon \\ Dept. of Aquatic Life Medicine, College of Ocean Science and Technology, Kunsan National University, \\ Gunsan 54150, Korea
}

\begin{abstract}
The author performed PCR-based genetic platform to measure the hierarchical dendrogram of Euclidean genetic distances of Korean scallop populations (KSP), particularly for Chlamys farreri, which was further compared with those of the Chinese scallop populations (CSP), by employing the with specifically designed oligonucleotide primer sets. The scallop is economically and ecologically very important bivalves in South Korea. Relatively, individuals of KSP population were fairly distantly related to that of CSP population, as shown in the hierarchical dendrogram of Euclidean genetic distances. Comparatively, individuals of KSP population were fairly distantly related to that of CSP population. Thus analysis of genetic difference between scallop populations could provide important statistics for fishery and aquaculture. Overall the results showed specific and/or conserved genetic loci between scallop populations. Information on the genetic distance of the bivalve would be helpful to understand scallop expansion or conservation in the coastal regions of South Korea. Specific markers developed by the author will be useful for the analysis of scallop population genetics and distribution in coastal region.
\end{abstract}

Key words : Euclidean genetic distances, Hierarchical dendrogram, Scallop population, Chlamys farrerit

\section{INTRODUCTION}

This scallop (Chlamys farreri) is, environmentally warmwater bivalve species, belonging to family Pectinidae, widely distributed on the coast of the Yellow Sea in the Korean Peninsula, as well as in several areas in Japan, South China Sea, Philippines, Indonesia under the natural surroundings. The clam is innate to benthic parts consisting of the rocks and pebbles regions from intertidal to shallow subtidal zone of $10 \mathrm{~m}$ in depth. Clams are also one of the most popular marine products in the Korean Peninsula because of their sense of taste and nourishing significance, and Koreans consume them abundantly. The coarse surface of this crustacean species is light gray and sculptures strong protuberance with scale-type, and the inside is white under the natural conditions. The shell is fan-type, and red-purple in color. Generally, there are marked differences of the shell weight, size, color and shape in Chlamys farreri according to the environmental circumstances of habitat such as prey, rock crystal, and water temperature. However, these kinds of Korean bivalve, which are recognized important physiologically (Oh et al., 2002; Park et al., 2012; Kim et al., 2015), reproductively (Chang et al., 1997; Park et al., 2006; Park \& Lee, 2008), as well as histologically (Park et al., 2006), are not genetically and/or molecular-biologically studied like other crustaceans. Principally, there are

\footnotetext{
Manuscript received October 20, 2017, Received in revised form November 22, 2017, Accepted November 30, 2017

${ }^{\dagger}$ Corresponding Author: Dr. Prof. Jong-Man Yoon, Department of Aquatic Life Medicine, College of Ocean Science and Technology, Kunsan National University, Gunsan 54150, Korea. Tel: +82-63-469-1887, E-mail: jmyoon@ @unsan.ac.kr

This is an Open Access article distributed under the terms of the Creative Commons Attribution Non-Commercial License (http:// creativecommons.org/licenses/by-nc/3.0) which permits unrestricted non-commercial use, distribution, and reproduction in any medium, provided the original work is properly cited.
} 
marked differences of the size, color and shape in Chlamys farreri in keeping with the ecological conditions of habitat such as nourish and hard period. There is a need to understand the genetic traits and composition of this clam population in order to evaluate precisely the patent genetic consequence. PCR-based molecular techniques have been applied to examine the genetic characters of various life organisms. Above all, the polymorphic and/or specific markers specific to the line, the species, the genus or the geographical populations have been applied for the of individuals and species, hybrid parentage and for the screening of DNA markers (Partis \& Wells, 1996; Callejas \& Ochando, 1998; Muchmore et al., 1998; McCormack et al., 2000; Park et al., 2005; Song \& Yoon, 2013; Oh \& Yoon, 2014). So far, specific fragments generated by this PCR method using arbitrary primers had good advantages for detecting DNA similarity and diversity between living being (Mc Cormack et al., 2000). The polymorphisms are determined by the banding patterns of amplified products at the specific positions by primers (Tassanakajon et al., 1998; Yoon \& Kim, 2004). Above all, the clustering analysis of the genetic distance between genera/species/populations of various fishes and crustaceans from the different geographic locates has been performed using PCR research is of small number (Kim et al., 2000; Tassanakajon et al., 1998; Klinbunga et al., 2000; McCormack et al., 2000; Yoon \& Park, 2002). The author undertook clustering analyses to disclose the Euclidean genetic distances between Korean and Chinese scallop population.

\section{MATERIALS AND METHODS}

Adductor muscle tissues were collected separately from two Chlamys farreri populations of Korean scallop population (KSP) and Chinese scallop population (CSP), respectively. Genomic DNA samples isolated from KSP and CSP population were PCR-amplified repeatedly. PCR research was performed on DNA samples extracted from a total of 22 individuals using eight oligonucleotides primers. DNA extraction should be accomplished according to the separation and extraction methods (Oh \&Yoon, 2014). After several washings, lysis buffer I $\left(155 \mathrm{mM} \mathrm{NH}_{4} \mathrm{Cl} ; 10\right.$ $\mathrm{mM} \mathrm{KHCO}_{3} ; 1 \mathrm{mM}$ EDTA) was added to the samples, and the mixture tubes were tenderly inverted. $600 \mu \mathrm{L}$ of chloroform was added to the mixture and then inverted (no phenol). Ice-cold $70 \% \mathrm{EtOH}$ was added, and then the samples were centrifuged at $19,621 \mathrm{~g}$ for 5 minutes to extract the DNA from the lysates. The concentration of the extracted genomic DNA was measured with the optical density value at $260 \mathrm{~nm}$ by a spectrophotometer (Beck man Coulter, Buckinghamshire, UK). The DNA pellets were then incubation-dried for more than 12 hours, maintained at $-40{ }^{\circ} \mathrm{C}$ until needed and then dissolved in the distilled water. Amplification products were separated by electrophoresis in 1.4\% agarose gels with TBE, using DNA ladder (Operon Technologies, Alameda, CA, USA) as DNA molecular weight marker and detected by staining with ethidium bromide. The author used the oligonucleotides primers to certify the genetic distances of Chlamys farreri individuals. Eight oligonucleotides primers (Operon Technologies, Alameda, CA, USA), OPD-01 (5'-ACCG CGAAGG-3'), OPD-02 (5'-GGACCCAACC-3'), OPD-04 (5'-TCTGGTGAGG-3'), OPD-08 (5'-GTGTGCCCCA-3'), OPD-09 (5'-CTCTGGAGAC-3'), OPD-15 (5'-CATCCGT GCT-3'), OPD-18 (5'-GAGAGCCAAC-3'), and OPD-19 (5'-CTGGGGACTT-3') were shown to generate the unique shared loci to each population and shared loci by the two scallop populations. Thus, the author used the primers to study the genetic variations and DNA polymorphisms of the scallop population. PCR was performed using programmable DNA Thermal Cycler (MJ Research Inc., Waltham, MA, USA) repeatedly. Eight oligonucleotides primers were shown to generate the unique shared loci to each population and shared loci by the two populations that could be obviously counted. After electrophoresis, gels were stained with ethidium bromide, illuminated with ultraviolet 
ray, and then photographed by photoman direct copy system (PECA Products, Beloit, WI, USA). Similarity matrix including bandsharing values (BS) between different individuals in the two scallop populations was produced according formula of Jeffreys \& Morton (1987) and YokeKqueen \& Radu (2006). The average of within-population similarity was calculated by pairwise comparison between individuals within a population. A hierarchical clustering tree was assembled using similarity matrices to yield a dendrogram, which was assisted by the Systat version 10 (SPSS Inc., Chicago, IL, USA).

\section{RESULTS AND DISCUSSION}

Author assessed genetic variation among individuals of the Korean scallop population and Chinese scallop population of Chlamys farreri, respectively, collected in the Yellow Sea and a site of Chinese sea by PCR analysis. DNA fragments acquired by eight oligonucleotides primers ranged in size from 100 to 4,500 bp in the scallop, as revealed in Fig. 1. The number of unique shared loci to each scallop population and number of shared loci by the two scallop populations generated by PCR research using eight oligonu- cleotides primers in the two scallop populations, respectively, as summarized in Table 1. The oligonucleotides primer OPD-01 generated 55 unique loci to each population, approximately 200, 250, 300, 400 and 450 bp, respectively, in the Korean scallop population. Specially, the primer OPD-09 generated 11 unique loci to each population, which were identifying each population, approximately $150 \mathrm{bp}$, in the Korean scallop population. The primer OPD-08 generated 77 unique loci to each population, which were determining each population, 500, 800, 1,000, 1,400, 2,000, 2,500 and 3,000 bp, in the Chinese scallop population. Remarkably, the primer OPD-15 distinguished 44 shared loci by the two scallop populations, major and/or minor fragments of sizes, which were identical in almost all of the samples. Numerous investigators researched the sizes of DNA fragments in the PCR structures of Eastern Pacific abalone (genus Haliotis) (Muchmore et al., 1998), blacklip abalone (Huang et al., 2000), Pollicipes mitella population (Song \& Yoon, 2013) and mollusk species (Oh \& Yoon, 2014). Multiple comparisons of average bandsharing values among scallop populations from two regions were generated according to the bandsharing values and similarity matrix, as illustrated in Table 2. Individuals from KSP population

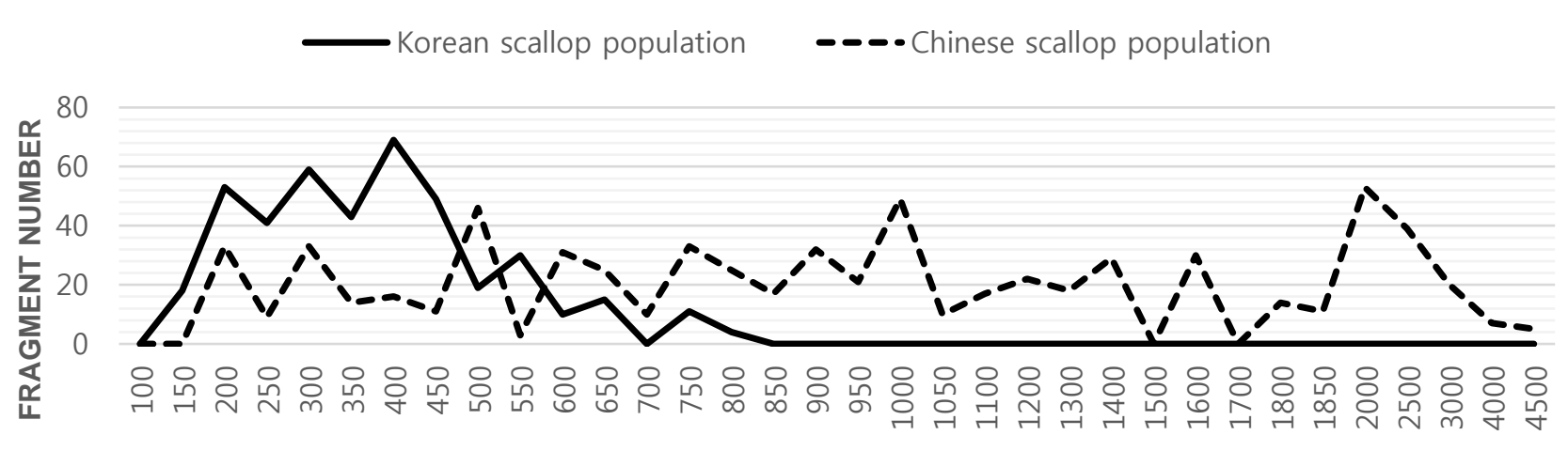

FRAGMENT SIZES

Fig. 1. Distribution of fragment sizes of Korean scallop population and Chinese scallop population of Chlamys farreri. Solid lines: Korean scallop population. Dotted lines: Chinese scallop population. The fragment numbers in each size interval have been computed from the integrated fragments obtained with every eight oligonucleotides primers. The higher fragment sizes (>850 bp) are much more observed in the Chinese scallop population. 
Table. 1. The number of unique shared loci to each scallop population and number of shared loci by the two scallop populations generated by PCR analysis using 8 oligonucleotides primers in the two scallop populations, respectively

\begin{tabular}{|c|c|c|c|}
\hline Item & \multicolumn{2}{|c|}{$\begin{array}{c}\text { No. of unique loci } \\
\text { to each scallop } \\
\text { population }\end{array}$} & \multirow{2}{*}{$\begin{array}{c}\text { No. of shared loci } \\
\text { by the two scallop } \\
\text { populations } \\
\text { Two scallop popula- } \\
\text { tions( } 11 \text { individuals } \\
\text { per population) }\end{array}$} \\
\hline $\begin{array}{c}\text { Primer } \backslash \\
\text { population }\end{array}$ & $\mathrm{KSP}$ & CSP & \\
\hline OPD - 01 & 55 & 33 & 0 \\
\hline OPD - 02 & 33 & 22 & 0 \\
\hline OPD - 04 & 33 & 44 & 0 \\
\hline OPD - 08 & 33 & 77 & 22 \\
\hline OPD - 09 & 11 & 55 & 0 \\
\hline OPD - 15 & 55 & 66 & 44 \\
\hline OPD - 18 & 0 & 44 & 0 \\
\hline OPD - 19 & 22 & 55 & 22 \\
\hline Total no. & 242 & 396 & 88 \\
\hline $\begin{array}{c}\text { Average no. } \\
\text { per primer }\end{array}$ & 30.25 & 49.5 & 11 \\
\hline
\end{tabular}

KSP: Korean scallop population

CSP: Chinese scallop population

Table 2. Multiple comparisons of average bandsharing values among two scallop populations were generated according to the bandsharing values and similarity matrix.

\begin{tabular}{ccc}
\hline \hline Population & KSP & CSP \\
\hline KSP & $0.798 \pm 0.060^{\mathrm{b}}$ & $0.185 \pm 0.030^{\mathrm{a}}$ \\
CSP & - & $0.832 \pm 0.073^{\mathrm{c}}$
\end{tabular}

KSP: Korean scallop population.

CSP: Chinese scallop population.

${ }^{\mathrm{a} \sim \mathrm{c}}$ Values with different superscript are significantly different, $P<0.05$.

Each value is a result of three different experiments.
$(0.798 \pm 0.060)$ exhibited lower bandsharing values than did individuals from CSP population $(0.832 \pm 0.073)(P<$ 0.05). In the end, the average bandsharing value of this study is higher than that the between bullhead population $(0.504 \pm 0.115)$ (Yoon \& Kim, 2004) and Spanish barbel species (0.71-0.81) (Callejas \& Ochando, 1998). As displayed in Fig. 2, the dendrogram obtained by the eight oligonucleotides primers indicates two genetic groups: cluster 1 (KSP 01, 02, 03, 04, 05, 06, 07, 08, 09, 10 and 11) and cluster 2 (CSP 12, 13, 14, 15, 16, 17, 18, 19, 20, 21 and 22). Among the twenty-two scallops, the shortest genetic distance that displayed significant molecular differences was between individuals 18 and 19 from the CSP population

\section{Cluster Tree}

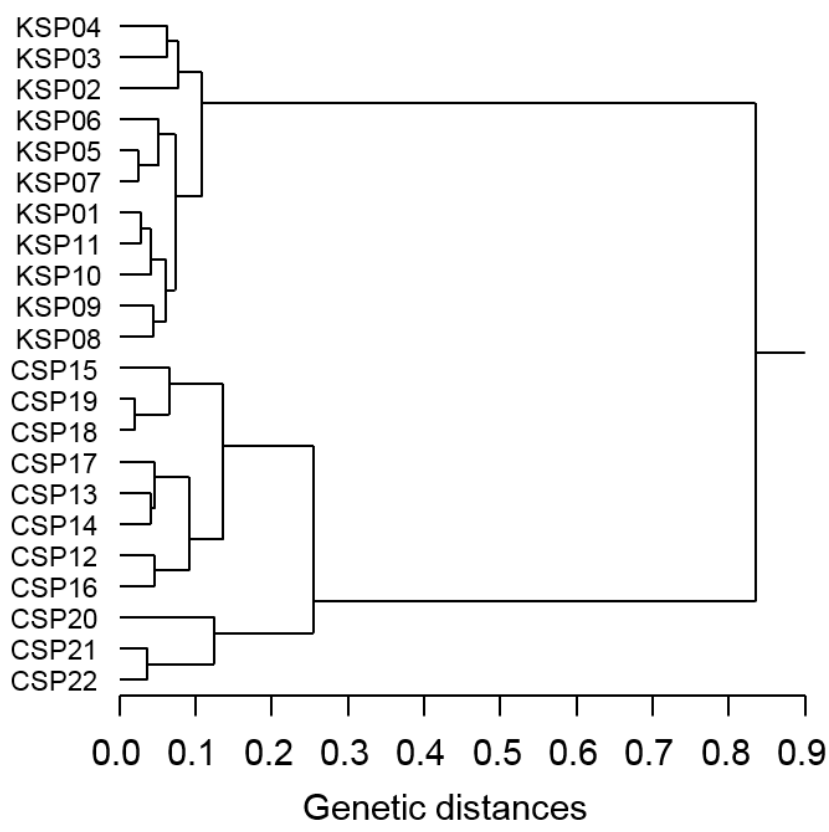

Fig. 2. Hierarchical dendrogram of Euclidean genetic distances acquired from two scallop populations. The manufacture among different individuals of Korean scallop population (KSP 01, 02, 03, 04, 05, 06, 07, 08, 09, 10 and 11) and Chinese scallop population (CSP 12, 13, 14, 15, 16, 17, 18, 19, 20, 21 and 22) produced according to the bandsharing values and similarity matrix. 
(genetic distance $=0.021$, while the longest genetic distance among the twenty-two individuals that exhibited significant molecular differences was between individuals KSP no. 07 and CSP no. 15 (genetic distance $=0.835$ ). The genetic distance between individuals approved the existence of close relatedness in the Korean scallop population. Comparatively, individuals of KSP population were fairly distantly related to that of CSP population, as shown in the hierarchical dendrogram of Euclidean genetic distances. The inter-population similarity indices and genetic distance values indicated that the Jamuna-Padma population pair of the Indian major carp (Catla catla) was genetically closer than the Halda-Jamuna and the Halda-Padma population pairs, which agreed with the geographical distances between them (Islam et al., 2005). They suggested that the RAPD technique could be used to discriminate between different river populations of major carp. A phylogenetic tree was constructed using UPGMA cluster analysis based on a total of 3,744 distinguishable fragments in gynogenetic clones from the silver crucian carp, Carassius auratus gibelio Block (Zhou et al., 2000). Clones A and P were the most closely related, whereas the most divergence was observed between clone D and clones E or F. The phylogenetic relationships among the 5 Haliotis species and one hybrid were carried out by calculating the distance coefficient and constructing a phylogenetic tree based on the PCR data (Kim et al., 2000). They were branched off into two clusters. Cluster I was formed by $H$. discus hannai, $H$. discus, H. gigantea, H. sieboldii, and the hybrid, which was subsequently divided into two sub-clusters. Cluster II contained only $H$. diversicolor aquatilis. Ultimately, they reported that PCR- bounded analysis is a powerful tool for determining the phylogenetic relationship between $6 \mathrm{Ha}$ liotis species. In invertebrates, cluster analysis of the pairwise population matrix, generated from genetic data, showed that geographically close populations be inclined to cluster together in the blacklip abalone (Huang et al., 2000). Overall, the population grouping of Chlamys farreri is esta- blished on morphological variations in shell weight, shell length, shell width, shell type, shell color and feet length. The prospective of oligonucleotides primer amplified polymorphic DNAs to determine diagnostic markers for breed, population, species and genus identification in shellfish has also been well identified (Partis \& Wells, 1996; Tassanakajon et al., 1998; Huang et al., 2000; Kim et al., 2000; Klinbunga et al., 2000; McCormack et al., 2000; Park et al., 2005; Song \& Yoon, 2013; Oh \& Yoon, 2014). PCR fragments revealed in this study may be valuable as a DNA marker the two geographical populations to discriminate.

\section{ACKNOWLEDGEMENTS}

The author would like to thank the reviewers who supported my treatise with thorough and shrewd correction. Detailed appreciations go to my laboratory collaborators for their help in sample collection and their aid with the practice of PCR analysis during the course of this research.

\section{REFERENCES}

Callejas C, Ochando MD (1998) Identification of Spanish barbel species using the RAPD technique. J Fish Biol 53:208-215.

Chang YJ, Park YJ, Lim HK (1997) Reproductive cycle of the cultured scallop, Patinopecten yessoensis in eastern waters of Korea. J Korean Aquacul Soc 10:133-141.

Huang BX, Peakall R, Hanna PJ (2000) Analysis of genetic structure of blacklip abalone (Haliotis rubra) populations using RAPD, minisatellite and microsatellite markers. Mar Biol 136:207-216.

Islam MS, Ahmed ASI, Azam MS, Alam MS (2005) Genetic analysis of three river populations of Catla catla (Hamilton) using randomly amplified polymorphic DNAs markers. Asian-Aust J Anim Sci 18:453-457.

Jeffreys AJ, Morton DB (1987) DNA fingerprints of dogs and cats. Anim Genet 18:1-15. 
Kim SK, Jung YH, Han SH, Oh YS, Ko MH, Oh MY (2000) Phylogenetic relationship among Haliotis spp. distributed in Korea by the RAPD analysis. Korean $\mathrm{J}$ Genet 22:43-49.

Kim YD, Lee J, Shim JM, Nam MM (2015) Growth characteristics of bay scallop (Argopecten irradians) reared in the southeast sea. Korean J Malacol 31:103-112.

Klinbunga S, Boonyapakdee A, Pratoomchat B (2000). Genetic diversity and species-diagnostic markers of mud crabs (Genus Scylla) in Eastern Thailand determined by RAPD analysis. Mar Biotechnol 2:180-187.

McCormack GC, Powell R and Keegan B (2000) Comparative analysis of two populations of the brittle star Amphiura filiformis (Echinodermata: Ophiuroidae) with different life history strategies using RAPD markers. Mar Biotechnol 2:100-106.

Muchmore ME, Moy GW, Swanson WJ, Vacquier VD (1998) Direct sequencing of genomic DNA for characterization of a satellite DNA in five species of Eastern Pacific abalone. Mol Mar Biol Biotechnol 7:1-6.

Oh BS, Chung CG, Kim SY (2002) Growth of bay scallop, Argopecten irradians at different rearing depths. J Korean Aquacul Soc 15:61-68.

Oh H, Yoon JM (2014) Genetic distances of three mollusk species investigated by PCR analysis. Dev Reprod 18: 43-49.

Park SY, Park JS, Yoon JM (2005) Genetic differences and variations in slipper lobster (Ibacus ciliatus) and deep sea lobster (Puerulus sewelli) determined by RAPD analysis. Korean J Genet 25:307-317.

Park YJ, Jung EY, Lee JY, Park KJ (2006) Ultrastructure of germ cell during spermatogenesis and reproductive cycle of the hanging cultured male scallop Patinopecten yessoensis (Pelecypoda: Pectinidae) on the East coast of Korea. Korean J Malacol 22:33-49.

Park GY, Lee KY (2008) Germ cell differentiations during oogenesis and reproductive cycle in female Jicon scallop, Chlamys farreri on the west coast of Korea. Dev Reprod 12:195-202.

Park GJ, Yoon SP, Park YJ, Song HI (2012) Effect of stocking density on growth and survival rate of the scallop, Chlamys farreri (Jones \& Preston, 1904) cultured in hanging culture in the west coast of Korea. Korean $\mathrm{J}$ Malacol 28:1-6.

Partis L, Wells RJ (1996) Identification of fish species using random amplified polymorphic DNA (RAPD). Mol Cell Probes 10:435-441.

Song YJ, Yoon JM (2013) Genetic differences of three Pollicipes mitella population identified by PCR analysis. Dev Reprod 17:199-205.

Tassanakajon A, Pongsomboon S, Jarayabhand P, Klinbunga S, Boonsaeng V (1998) Genetic structure in wild populations of black tiger shrimp (Penaeus monodon) using randomly amplified polymorphic DNA analysis. J Mar Biotechnol 6:249-254.

Yoon JM, Park HY (2002) Genetic similarity and variation in the cultured and wild crucian carp (Carassius carassius) estimated with random amplified polymorphic DNA. Asian-Aust J Anim Sci 15:470-476.

Yoon JM, Kim JY (2004) Genetic differences within and between populations of Korean catfish (S. asotus) and bullhead (P. fulvidraco) analysed by RAPD-PCR. AsianAust J Anim Sci 17:1053-1061.

Yoke-Kqueen C, Radu S (2006) Random amplified polymorphic DNA analysis of genetically modified organisms. J Biotechnol 127:161-166.

Zhou L, Wang Y, Gui JF (2000) Analysis of genetic heterogeneity among five gynogenetic clones of silver crucian carp, Carassius auratus gibelio Block, based on detection of RAPD molecular markers. Cytogenet Cell Genet 88:133-139. 